\section{Reseña / Cartografía social: teoría y método. Estrategias para una eficaz transformación comunitaria}

Juan Manuel Diez Tetamanti (2018). 1ra. ed. Buenos

Aires: Biblos. ISBN 978-987-691-648-6, 102 pp.

\section{Por Lelis Ailin Feü}

Instituto de Investigaciones Geográficas de la Patagonia (Universidad Nacional de San Juan Bosco). Consejo Nacional de Investigaciones Científicas y Técnicas. Secretaría de Ciencia, Tecnología e Innovación Productiva del Chubut. Argentina.

lelisfeu@gmail.com
Investigación y extensión universitaria / Reseña de libros

La cartografía social es una forma de construcción colectiva de conocimiento. El encuentro con otros para poder abordar lo territorial, desde la experiencia, desde el espacio vivido, permite la creación de mapas cargados de historia, política y relaciones, de vida social. Este producto colectivo es flexible y en continua construcción, al igual que la metodología misma.

El libro consta de 7 capítulos en los cuales explica el proceso de la metodología cartografía social a través de distintas experiencias. El prólogo es de Alfredo Carballeda.

Se hace referencia a quiénes son los cartógrafos sociales y se aclara que todos los que participan del taller lo son. Allí se los motiva y se los invita a jugar y a producir de manera colectiva.

El autor expone de modo autorreferencial cómo fue el proceso propio de pensar en la metodología a través de una experiencia con un alumno de nivel medio, a partir del cual comenzó a cuestionarse la idea de los mapas tradicionales. Trabaja todas aquellas representaciones que los sujetos tenemos en la mente como mapas experienciales y sobre cómo las referencias de un espacio conocido nos permiten la formulación de ese territorio vivido, lo que habilita la construcción colectiva de mapas.

Se realiza un recorrido por la discusión teórica que da fundamento a la metodología, se efectúa un análisis crítico de la cartografía tradicional, lo que le posibilita ahondar en una nueva y diferente forma de creación de mapas. La metodología planteada busca esfumar las diferencias entre sujeto investigador y sujeto investigado, ya que ambos participan y construyen conjuntamente sin distinciones y desde su propio conocimiento producto de la experiencia.

El libro se centra en una explicación sencilla de los cinco pasos necesarios para el desarrollo de la cartografía social y describe cada uno de ellos. Hay una mención especial para el elemento "derrotero" de la metodología, ya que será este el que marque el rumbo que tomará el taller en el cual se desarrolla el trabajo conjunto y comunitario. El vocabulario que se utilice en el mismo debe ser claro y puede tener distintos objetivos. Se plantean algunos ya trabajados, aunque siempre está abierta la posibilidad a modificaciones, cambios o propuestas de nuevos derroteros.

Esta metodología se fue construyendo con el trabajo comunitario, y lejos está de estar acabada. Cada taller permite aprender nuevas formas de realizarla, nuevos objetivos y contenidos diferentes. Principalmente, la cartografía social es un inicio o una forma de generar transformaciones comunitarias de nuestros territorios. 